\title{
Abnormal Forearm Vascular Responses in the Carcinoid Syndrome: The Role of Kinins and Kinin-generating System*
}

\author{
Dean T. Mason $\dagger$ and Kenneth L. Melmon $\ddagger$ \\ (From the Cardiology Branch and the Experimental Therapeutics Branch, National Heart \\ Institute, Bethesda, Md.)
}

Although the overproduction of serotonin remains the hallmark of the carcinoid syndrome (1-3), recently attention has been focused on other biologically active substances elaborated by carcinoid tumors (3-5). A variety of clinical and pathologic features distinct from those ordinarily associated with the ileal carcinoid tumor have been described, and the importance attributed to serotonin as the sole mediator of the symptoms has been challenged (3-8). Thus, the carcinoid tumor may possess multiple endocrine properties capable of producing a spectrum of clinical manifestations $(2,3,9,10)$. The findings that infusion of synthetic bradykinin to normal subjects and patients with the carcinoid syndrome produces typical flushes (4), that some carcinoid tumors contain an enzyme, kallikrein, capable of producing lysyl-bradykinin $(4,11)$, and that bradykinin may be released into the hepatic vein during epinephrine-induced flushes $(12,13)$ suggest that the endogenous nonapeptide bradykinin may play an important role in the production of the flush.

This investigation was undertaken to search for additional evidence that bradykinin is an important participant in the production of the carcinoid flush. We considered the possibility that if a vasoactive substance is released into the circulation during a flush reaction, then certain vascular responses in carcinoid patients might be abnormal. Accordingly, this paper describes studies on the

* Submitted for publication May 4, 1966; accepted July 21, 1966.

Supported in part by research grant HE 09964 from the National Institutes of Health, U. S. Public Health Service.

† Address requests for reprints to Dr. Dean T. Mason, Cardiology Branch, National Heart Institute, Bethesda, Md. 20014.

$\$$ Present address: University of California Medical Center, San Francisco, Calif. effects of bradykinin, epinephrine, methoxamine, and reflex stimulation of the sympathetic nervous system (cold pressor test) on a specific vascular bed, that of the forearm. The effects of these interventions on both the resistance and capacitance vessels were examined in normal subjects and carcinoid patients. In addition, an understanding of the pharmacodynamics of induced and spontaneous flushes was accomplished by the determination of tumor kallikrein and kinin peptide in arterial plasma and comparison of the levels of these substances with the circulatory changes observed.

\section{Methods}

\section{Clinical materials}

The effects of bradykinin, epinephrine, cold stimulation, and methoxamine on forearm vascular dynamics were determined in ten normal subjects (18 to 38 years of age) and in eight patients with the carcinoid syndrome (29 to 57 years of age). The diagnosis of the carcinoid syndrome was established in each of the eight patients who had flushes and several other characteristics of the syndrome by measurement of 24-hour excretions of 5-hydroxyindoleacetic acid (5-HIAA) (14) (range 40 to $873 \mathrm{mg}$, normal less than $9 \mathrm{mg}$ ) ; concentrations of platelet serotonin (15) (range 0.64 to $3.54 \mu \mathrm{g}$ per $\mathrm{mg}$ protein, normal less than $0.4 \mu \mathrm{g}$ per $\mathrm{mg}$ protein); and chromatographic determination of abnormalities of urinary indoles (16). Six of the patients had primary ileal tumors, and two, C.Sh. and E.G., had primary bronchial tumors. In the normal subjects, 24-hour urinary 5-HIAA and platelet serotonin were normal.

\section{Hemodynamic methods}

A plethysmographic technique was employed for the measurement of forearm blood flow and the estimation of venous tone. This technique has been described in detail, and its reliability and reproducibility have been thoroughly substantiated elsewhere $(17,18)$. Changes in forearm volume were determined by a Whitney mercury in rubber strain gauge plethysmograph (19) on the midforearm. Forarm venous pressure was measured 
through a 14-cm PE no. 50 catheter introduced into a large vein at the wrist and advanced so that its tip lay just distal to the mercury in rubber gauge. The forearm was elevated so that the venous pressure was nearly zero (20). A sphygmomanometric cuff was placed around the wrist and inflated to a level exceeding systolic arterial pressure just before each venous occlusion. A $13 \mathrm{~cm}$ wide sphygmomanometric cuff was placed around the upper arm, and forearm venous occlusion was produced by suddenly inflating this cuff to a pressure below the diastolic arterial pressure. Arterial pressure was measured through an indwelling arterial needle in the brachial artery of the opposite forearm.

Forearm blood flow was calculated from the change in forearm circumference during venous occlusion $(19,21$, 22) and was expressed in milliliters per $100 \mathrm{~g}$ tissue per minute. Forearm vascular resistance was calculated as the ratio of mean arterial pressure to forearm blood flow, expressed in millimeters $\mathrm{Hg}$ per milliliter per $100 \mathrm{~g}$ per minute. The pressure-volume characteristics of the capacitance vessels, venous tone expressed in millimeters $\mathrm{Hg}$ per milliliter, were calculated by determining the ratio of the increment in venous pressure to the increment in forearm volume that occurred after the venous occlusion cuff was inflated. Venous pressure and volume were measured 10 seconds after the venous occlusion. Since both pressure and volume rose in an almost linear fashion immediately after occlusion, this ratio was not altered significantly by the precise time during the first 30 seconds after occlusion at which the measurements were made. The fact that the initial venous pressure was nearly zero provided a constant reference point for the venous pressure-volume relationship and enabled the determinations to be made at a point where this relationship is known to be linear. Although some investigators have occasionally noted rising of venous pressure at different rates in different veins after venous occlusion (23, 24 ), other studies have shown no observable differences in venous filling pressure from veins located in different positions on the forearm when the catheters are placed carefully $(17,18)$.

All studies were performed with subjects in the basal postabsorptive state. After placement of the catheters and needles, 15 minutes was permitted to elapse to achieve a stable state. Four control venous occlusion curves were obtained at $\frac{1}{2}$-minute intervals to determine basal forearm blood flow and forearm venous tone. Synthetic bradykinin, ${ }^{1} 0.4 \mu \mathrm{g}$ per $\mathrm{kg}$, representing doses ranging from 20 to $35 \mu \mathrm{g}$ for both groups of individuals, was rapidly administered through a vein in the opposite forearm from the one on which the plethysmograph was mounted. Venous occlusion curves were recorded at 20- to 30 -second intervals over the next 3 to 5 minutes. At least 20 minutes was permitted to elapse between studies to allow the return of the basal state. After the redetermination of control values, the vascular effects of epinephrine, ${ }^{2} 5 \mu \mathrm{g}$

1 Obtained from Sandoz Pharmaceuticals, Hanover, N. J. The chemical and biologic identity between natural and synthetic bradykinin has been established (25).

2 Obtained from Parke, Davis and Co., Detroit, Mich. rapidly administered intravenously to both groups, were determined by the acute occlusion technique. Cold stimulation was then performed by immersion of the hand opposite the one from which flow measurements were recorded into ice water for 2 minutes. So that the activity of the sympathetic nervous system in both groups could be estimated, the subjects carried out the Valsalva maneuver by maintaining an expiratory pressure of 40 $\mathrm{mm} \mathrm{Hg}$ for 10 seconds while systemic arterial pressure was recorded. After the return of the basal state, to observe the effects of a sympathomimetic agent other than epinephrine, we assessed the effects of the rapid injection of $1 \mathrm{mg}$ methoxamine ${ }^{3}$ by the acute occlusion technique.

In three of the carcinoid patients, C.Sh., E.G., and M.Q., it was possible to record the vascular changes that occurred in the forearm before and during a spontaneous flush. In all of these patients the forearm blood flow and direct arterial pressure measurements were obtained, and, in E.G., venous tone was also measured.

\section{Kallikrein and bradykinin determinations}

In eight normal subjects and seven carcinoid patients, the plasma level of the bradykinin-forming enzyme, anionic kallikrein, was determined in samples taken from a systemic artery before and 2 minutes after the administration of epinephrine and before and 2 minutes after the initiation of cold stimulation. In addition, in four of the carcinoid patients systemic arterial bradykinin was measured at the same time as the kallikreins before and after administration of epinephrine. Furthermore, in one of these patients, C.G., hepatic venous bradykinin levels were determined before and after epinephrine. The hepatic venous blood samples were obtained by catheterization via a saphenous vein. During these interventions in the carcinoid patients, kallikrein and kinin determinations were carried out when the induced flush was most prominent.

Determinations of arterial kallikrein and bradykinin were carried out in patient C.G. at 1-minute intervals during three successive flushes, each induced by the injection of $5 \mu \mathrm{g}$ epinephrine. A 20 -minute waiting period was allowed between each injection. In a normal subject, S.M., arterial kallikrein and bradykinin determinations were performed in an identical manner during three successive injections of $5 \mu \mathrm{g}$ epinephrine.

In a carcinoid patient, M.Q., in whom the vascular effects of a spontaneous flush were observed, arterial bradykinin was determined before and 1 minute after onset of the flush.

Tumor anionic kallikrein in brachial arterial plasma. Ten $\mathrm{ml}$ of whole blood was withdrawn from the brachial artery into siliconized syringes during control periods and at various times after injection of epinephrine, immersion of the hand in ice water, or the appearance of a spontaneous flush. The blood was placed in siliconized tubes and centrifuged for 20 minutes at $4^{\circ} \mathrm{C}$, and $1-\mathrm{ml} \mathrm{sam}$ ples of the plasma were diluted to $100 \mathrm{ml}$ with distilled

3 Obtained from Burroughs Wellcome and Co., Tuckahoe, N. Y. 
water. The diluted plasma was added to $0.5 \mathrm{~g}$ DEAEcellulose $(0.9 \mathrm{mEq}$ per $\mathrm{g})$ with constant stirring, and the solution was rapidly adjusted to $\mathrm{pH}$ 7.1. When the $\mathrm{pH}$ was stable, the solution containing the resin was stirred for a minimum of 3 hours and a maximum of 12 hours at $4^{\circ} \mathrm{C}$. The DEAE-cellulose was then filtered on a Buchner funnel and the resin washed with two portions $(150 \mathrm{ml})$ of distilled water or until the filtrate was clear. The wash was discarded, and the absorbed kallikrein eluted with $70 \mathrm{ml}$ potassium phosphate buffer, $\mathrm{pH} 6.0$. The eluate was adjusted to $\mathrm{pH} 6.0$, dialyzed for 16 hours against distilled water $(1: 100,000)$ at $4^{\circ} \mathrm{C}$, readjusted to $\mathrm{pH} 6.0$, and heated in a water bath for 5 minutes at $55^{\circ} \mathrm{C}$ with constant agitation. The heated dialyzate was then freeze-dried and stored in dried form until the time of assay, when it was diluted in $4 \mathrm{ml}$ of cold deionized water and kept cold in ice until assay. Kallikrein activity, expressed in Frey units (FU), was assayed by incubation with an excess amount of substrate (kininogen) within the isolated uterus bath, and the uterine response to kinin formed by this reaction was measured by previously described methods $(4,11)$. Kallikrein activity determined in this fashion includes only enzyme of the type found in tumor. Plasma kallikrein

EPINEPHRINE
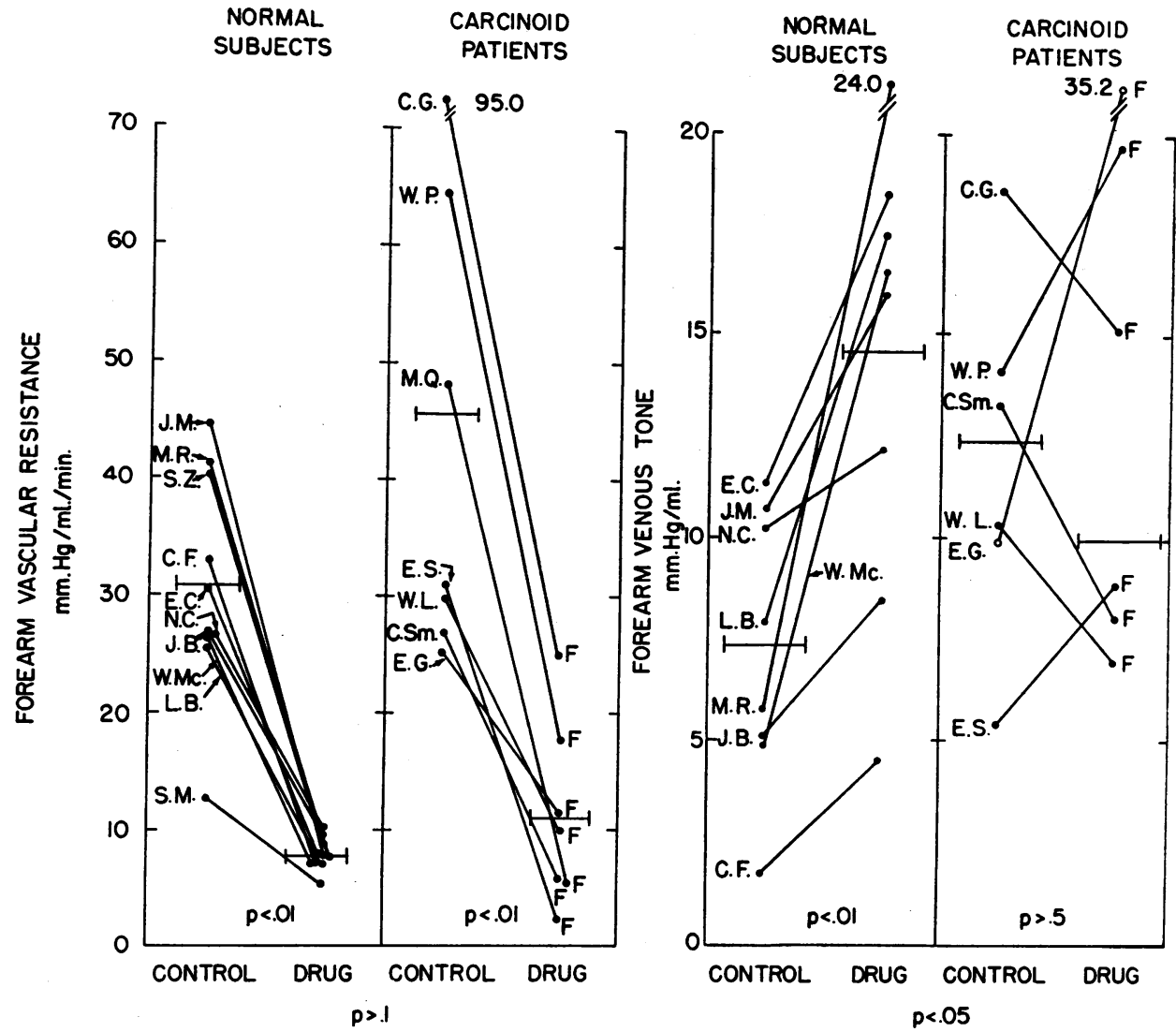

Fig. 1. VALUES FOR FOREARM VASCULAR RESISTANCE AND FOREARM VENOUS TONE DURING THE CONTROL PERIOD AND AFTER THE ADMINISTRATION OF EPINEPHRINE IN NORMAL SUBJECTS AND PATIENTS WITH CARCINOID TUMORS. In each panel, measurements in the basal state are on the left, and those at the time of the maximal effect occurring after the drug are on the right. The horizontal bars represent mean values. Each subject or patient is designated by initials placed next to the experimental data in this and all subsequent figures. $F$ indicates the occurrence of a cutaneous flush. In this and subsequent figures, the upper level of probability values expresses the statistical significance of changes produced by the intervention in each group of individuals, and the lower level of values compares the significance of the difference of the changes induced by the intervention between the normal subjects and carcinoid patients. In the last panel the values for venous tone in patient E.G. (open circles) are not included in the calculation of the mean values or probability analysis. 
TABLE I

Circulatory effects of bradykinin, epinephrine, cold stimulation, and methoxamine in normal subjects and carcinoid patients*

\begin{tabular}{|c|c|c|c|c|c|c|c|c|}
\hline \multicolumn{5}{|c|}{ Normal subjects } & \multicolumn{4}{|c|}{ Carcinoid patients } \\
\hline \multicolumn{2}{|c|}{ MAP } & FBF & FVR & FVT & MAP & FBF & FVR & FVT \\
\hline \multicolumn{2}{|c|}{$m m H g$} & $\mathrm{ml} / 100 \mathrm{~g} / \min$ & $\underset{100 \mathrm{~g} / \mathrm{min})}{m \mathrm{Hg} /(\mathrm{ml} /}$ & $\begin{array}{l}m m H g / m l \\
\text { Bradykinin }\end{array}$ & $m m \mathrm{Hg}$ & $\mathrm{ml} / 100 \mathrm{~g} / \mathrm{min}$ & $\underset{100 \mathrm{~g} / \mathrm{min})}{\mathrm{Hg} /(\mathrm{ml} /}$ & $m m H g / m_{\uparrow}$ \\
\hline $\begin{array}{l}C \pm \text { SEM } \\
\text { Brad. } \\
p\end{array}$ & $\begin{array}{c}93.3 \pm 4.2 \\
72.7 \pm 3.6 \\
<0.01 \\
n=10\end{array}$ & $\begin{array}{c}2.65 \pm 0.89 \\
4.12 \pm 0.61 \\
<0.01\end{array}$ & $\begin{array}{c}35.3 \pm 2.5 \\
21.8 \pm 2.9 \\
\quad<0.01\end{array}$ & $\begin{array}{c}7.5 \pm 1.4 \\
5.8 \pm 0.9 \\
<0.01\end{array}$ & $\begin{array}{c}87.7 \pm 4.2 \\
79.8 \pm 4.3 \\
<0.01 \\
n=7\end{array}$ & $\begin{array}{c}2.15 \pm 0.25 \\
2.98 \pm 0.43 \\
<0.01\end{array}$ & $\begin{array}{c}46.3 \pm 9.2 \\
32.6 \pm 7.1 \\
<0.01\end{array}$ & $\begin{array}{c}11.8 \pm 2.1 \\
8.1 \pm 1.4 \\
<0.01\end{array}$ \\
\hline \multicolumn{9}{|c|}{ Epinephrine } \\
\hline $\begin{array}{l}\text { C } \\
\text { Epi. } \\
\text { p }\end{array}$ & $\begin{array}{c}92.4 \pm 4.4 \\
73.6 \pm 3.6 \\
<0.01 \\
\mathrm{n}=10\end{array}$ & $\begin{array}{r}3.20 \pm 0.33 \\
10.65 \pm 1.15 \\
<0.01\end{array}$ & $\begin{array}{c}30.7 \pm 3.0 \\
7.8 \pm 1.3 \\
<0.01\end{array}$ & $\begin{array}{c}7.3 \pm 1.1 \\
14.7 \pm 2.3 \\
\quad<0.01 \\
\text { Cold stimulation }\end{array}$ & $\begin{array}{c}89.7 \pm 3.8 \\
71.7 \pm 5.8 \\
<0.01 \\
\mathrm{n}=7\end{array}$ & $\begin{array}{c}2.43 \pm 0.34 \\
9.87 \pm 0.21 \\
<0.01\end{array}$ & $\begin{array}{c}45.8 \pm 9.1 \\
11.1 \pm 3.0 \\
<0.01\end{array}$ & $\begin{array}{c}12.4 \pm 1.8 \\
10.0 \pm 3.6 \\
>0.5\end{array}$ \\
\hline $\begin{array}{l}\text { C } \\
\text { Ice } \\
\text { p }\end{array}$ & $\begin{array}{c}95.8 \pm 3.6 \\
115.9 \pm 6.3 \\
<0.01 \\
n=9\end{array}$ & $\begin{array}{c}2.58 \pm 0.33 \\
2.12 \pm 0.35 \\
\quad<0.05\end{array}$ & $\begin{array}{c}37.4 \pm 2.7 \\
64.0 \pm 7.9 \\
<0.01\end{array}$ & $\begin{array}{c}7.0 \pm 0.7 \\
14.6 \pm 2.7 \\
<0.01 \\
\text { Methoxamine }\end{array}$ & $\begin{array}{c}88.9 \pm 4.5 \\
96.0 \pm 5.6 \\
<0.05 \\
n=8\end{array}$ & $\begin{array}{c}2.43 \pm 0.32 \\
2.46 \pm 0.36 \\
>0.5\end{array}$ & $\begin{array}{c}45.0 \pm 8.6 \\
48.8 \pm 11.0 \\
>0.3\end{array}$ & $\begin{array}{c}11.9 \pm 1.9 \\
13.7 \pm 5.4 \\
>0.1\end{array}$ \\
\hline $\begin{array}{l}\text { C } \\
\text { Meth. } \\
\text { p }\end{array}$ & $\begin{array}{c}92.7 \pm 3.5 \\
99.0 \pm 4.0 \\
<0.01 \\
\mathrm{n}=9\end{array}$ & $\begin{array}{c}2.45 \pm 0.23 \\
2.41 \pm 4.0 \\
\quad>0.3\end{array}$ & $\begin{array}{c}39.1 \pm 2.7 \\
42.5 \pm 3.1 \\
<0.01\end{array}$ & $\begin{array}{c}7.2 \pm 1.1 \\
7.8 \pm 1.3 \\
>0.05\end{array}$ & $\begin{array}{c}81.3 \pm 3.8 \\
91.3 \pm 3.9 \\
<0.01 \\
n=4\end{array}$ & $\begin{array}{c}2.39 \pm 0.17 \\
2.18 \pm 0.12 \\
>0.1\end{array}$ & $\begin{array}{c}34.9 \pm 4.0 \\
42.8 \pm 4.4 \\
<0.01\end{array}$ & $\begin{array}{c}12.0 \pm 1.9 \\
12.2 \pm 3.4 \\
>0.3\end{array}$ \\
\hline
\end{tabular}

* Abbreviations: MAP $=$ mean arterial pressure, $\mathrm{FBF}=$ forearm blood flow, $\mathrm{FVR}=$ forearm vascular resistance, $\mathrm{FVT}=$ forearm venous tone, $\mathrm{C}=$ initial control observations, brad. = bradykinin, epi. = epinephrine, meth. = methoxamine, and $\mathrm{n}=$ number of subjects or patients.

activated by dilution is not absorbed onto DEAE-cellulose. Kininogen was prepared by the method of Webster and Pierce (26).

Duplicate samples were always carried through the procedure, and recoveries of added ( $0.25 \mathrm{FU})$ human urinary or tumor kallikrein ranged from 48 to $61 \%$. Whenever substantial activity was detected, a sample containing $0.1 \mathrm{FU}$ was incubated with $200 \mu \mathrm{g}$ soybean trypsin inhibitor at $29^{\circ} \mathrm{C}$ for 4 minutes and then assayed as above. If more than $75 \%$ inhibitor activity was seen, the sample was considered contaminated with plasma kallikrein and discarded. Likewise, the sample was discarded if it produced immediate contraction of the uterus strip without added substrate.

Kinin peptide in brachial arterial and hepatic venous plasma. The method used has been described elsewhere in detail $(4,11,13,27)$. In brief, $10 \mathrm{ml}$ of arterial blood was rapidly (within 15 seconds) aspirated into a siliconized syringe containing $1.0 \mathrm{ml}$ dilute phosphoric acid and $0.2 \mathrm{ml}$ soybean trypsin inhibitor $(10 \mathrm{mg}$ per $\mathrm{ml}$ saline). The peptide was then absorbed onto IRC-50 $\left(\mathrm{H}^{+}\right)$, eluted with ammonium formate, and assayed on the estrus rat uterus.

\section{Results}

The values for mean arterial pressure and forearm blood flow, vascular resistance, and venous tone during the control periods showed some scatter in both normal subjects and carcinoid pa- tients (Figure 1). However, in any given individual these measurements before the interventions showed very little variation and were not statistically significant $(p>0.5)$. The resting values for arterial pressure and forearm blood flow and vascular resistance were not significantly different $(p>0.05)$ between the two groups of individuals. However, the control values for venous tone in the carcinoid patients were significantly greater $(p<0.05)$ than those in the normal subjects.

\section{Bradykinin: normal subjects, hemodynamic find- ings}

In the ten normal subjects, the vascular responses to bradykinin are presented in Table I. The drug resulted in a fall of arterial pressure, a rise in forearm flow, a decline in vascular resistance, and a rise followed by a fall in venous tone.

\section{Bradykinin: carcinoid subjects, hemodynamic findings}

Bradykinin was administered to seven patients; the data are shown in Table $I$. These responses did not differ significantly $(p>0.5)$ from those observed in the normal subjects. In addition, in 


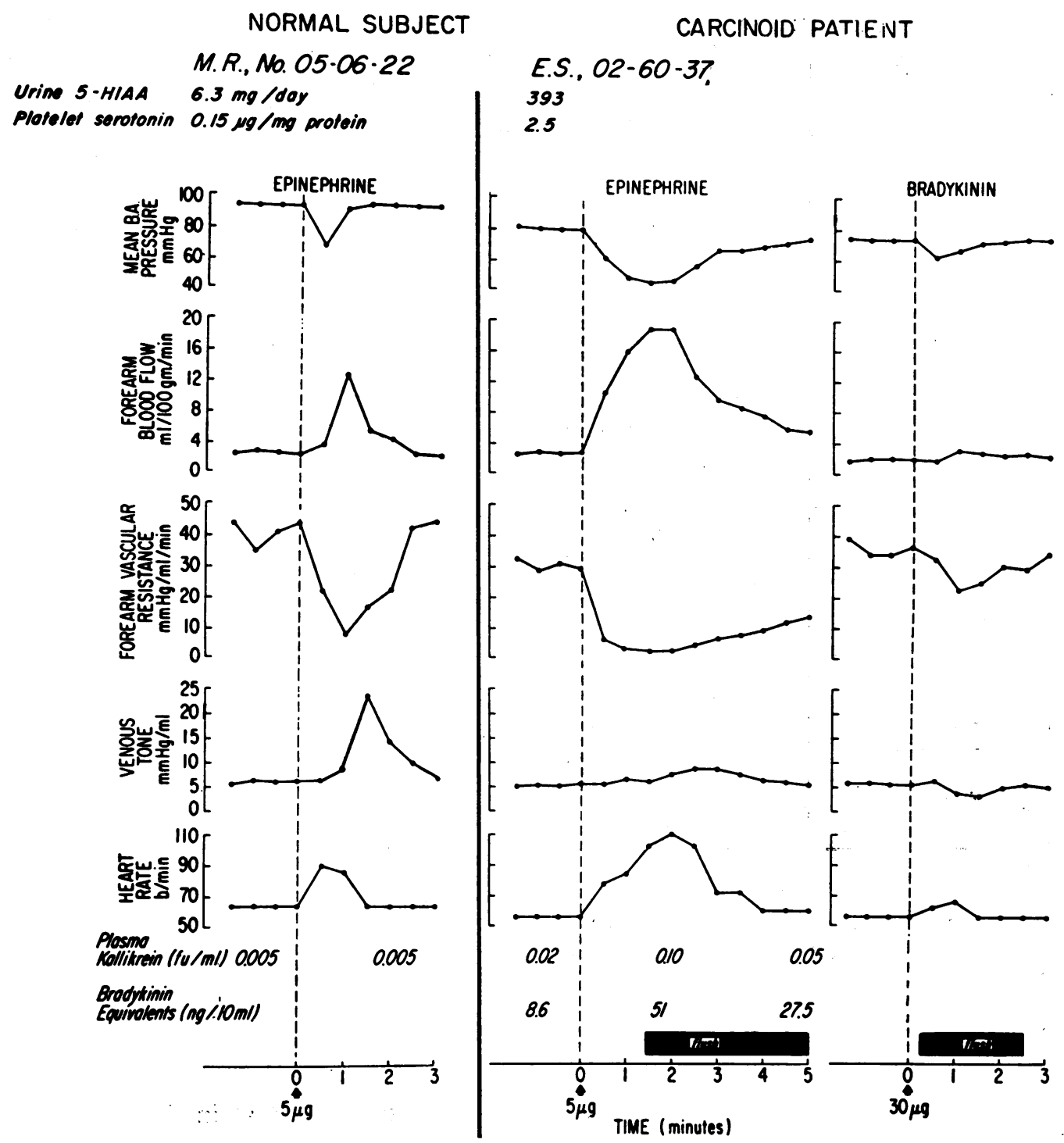

Fig. 2. Serial determinations of arterial pressure (BA), Forearm blood flow, Forearm vascuLAR RESISTANCE, VENOUS TONE, HEART RATE, PLASMA KALLIKREIN, AND BRADYKININ BEFORE AND AFTER EPINEPHRINE AND BEFORE AND AFTER BRADYKININ IN NORMAL SUBJECT M.R. AND CARCINOID PATIENT E.S. The temporal relationship of the flushes observed in the carcinoid patient are indicated by the solid horizontal bars. The values for urinary 5-hydroxyindoleacetic acid (5-HIAA), platelet serotonin, and postValsalva arterial pressure overshoot were obtained in the control state. FU $=$ Frey units.

each patient, a cutaneous flush was observed that was similar in nature, onset, and duration to those noted in the normal subjects. A paradoxical sustained rise in venous tone after bradykinin in patient E.G. will be considered separately.

\section{Epinephrine: normal subjects}

Hemodynamic findings. The results in the normal subjects are presented in Table I and Figure
1. The predominant effect on the mean arterial pressure was a fall immediately preceded by a brief rise in mean pressure of less than $10 \mathrm{~mm} \mathrm{Hg}$ lasting about 5 seconds. Since forearm blood flow rose, forearm vascular resistance was reduced; venous tone was increased. The maximal depression of mean pressure usually occurred between 30 and 60 seconds after the injection, and the increase in forearm blood flow rose to a peak about $30 \mathrm{sec}$ - 


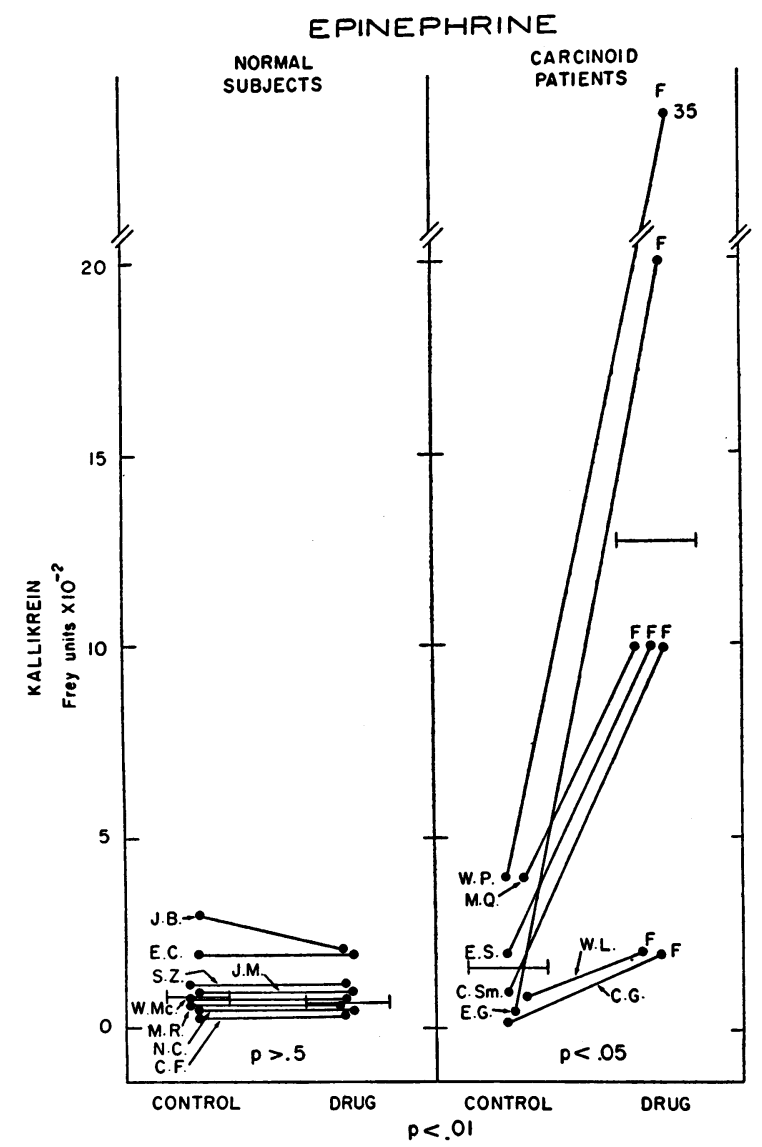

FIG. 3. VALUES FOR ARTERIAL PLASMA KALLIKREIN DURING THE CONTROL PERIOD AND AFTER EPINEPHRINE IN NORMAL SUBJECTS AND CARCINOID PATIENTS. For explanation of comparisons analyzed by probability values, see legend to Figure 1.

onds after the nadir of the pressure fall. Sequential measurements from one normal subject are shown in Figure 2. In none of the normal subjects was a cutaneous flush elicited by the drug.

Kallikrein and bradykinin. The values for systemic arterial kallikrein during the control period and after administration of epinephrine are summarized in Figure 3. There was no significant change in the level of the enzyme as a result of epinephrine $(p>0.5)$. In subject S.M., bradykinin was also measured in brachial arterial blood. The amount of kinin was unaltered by epinephrine; it was $5.4 \mu \mathrm{g}$ per $10 \mathrm{ml}$ before and $4.5 \mu \mathrm{g}$ per $10 \mathrm{ml}$ after the drug.

\section{Epinephrine: carcinoid patients}

Hemodynamic findings. The effects of epinephrine on vascular dynamics in seven carcinoid pa- tients are given in Table I and Figure 1. It lowered the mean pressure, elevated forearm blood flow, and, therefore, lowered the vascular resistance. Although there was no significant difference in the maximal decline of vascular resistance or in the temporal relationships regarding the onset of fall of pressure and rise of flow between the normal subjects and carcinoid patients, the time course of the response in the two groups differed markedly. The duration of the fall in vascular resistance was significantly more prolonged $(p<$ 0.01 ) in the carcinoid patients than in the normal subjects (Figures 2 and 4 ). In the former group, resistance was still reduced in four patients $5 \mathrm{~min}$ utes after epinephrine, when measurements were discontinued, and up to 4 minutes in two patients. In contrast, the duration of the fall in resistance in the normal subjects was considerably shorter, between $1 \frac{1}{2}$ to $2 \frac{1}{2}$ minutes in each subject. The reduced resistance in the carcinoid patients was brought about by both a prolonged decline in pressure and a rise in forearm flow. As in the normal subjects, a small transient elevation of mean pressure was observed just before the more prominent fall of pressure in five of the carcinoid patients. Also in contrast to the normal subjects, a severe cutaneous flush was observed for several minutes after epinephrine in the carcinoid patients. These flushes occurred about 45 to 120 seconds after the injection of epinephrine and correlated with the prolonged period of reduced resistance.

The response of venous tone in the six carcinoid patients in which this variable was measured was also different from that in the normal subjects. Although the average venous tone decreased in the carcinoid patients, this change was not statistically significant $(p>0.5)$. In three of the patients the venous tone actually fell after the drug. In the carcinoid patient E.G., who exhibited an atypical pressor response to epinephrine, cold stimulation, and bradykinin-induced flushes and during spontaneous flushes, there was a marked elevation of venous tone after epinephrine. The values for venous tone in this patient are not included in this section.

Kallikrein and bradykinin. Although the average control values for kallikrein were higher in the carcinoid patients than in the normal subjects, this difference was not statistically significant $(\mathrm{p}>$ 0.3 ) (Figure 3 ). The effects of epinephrine on 


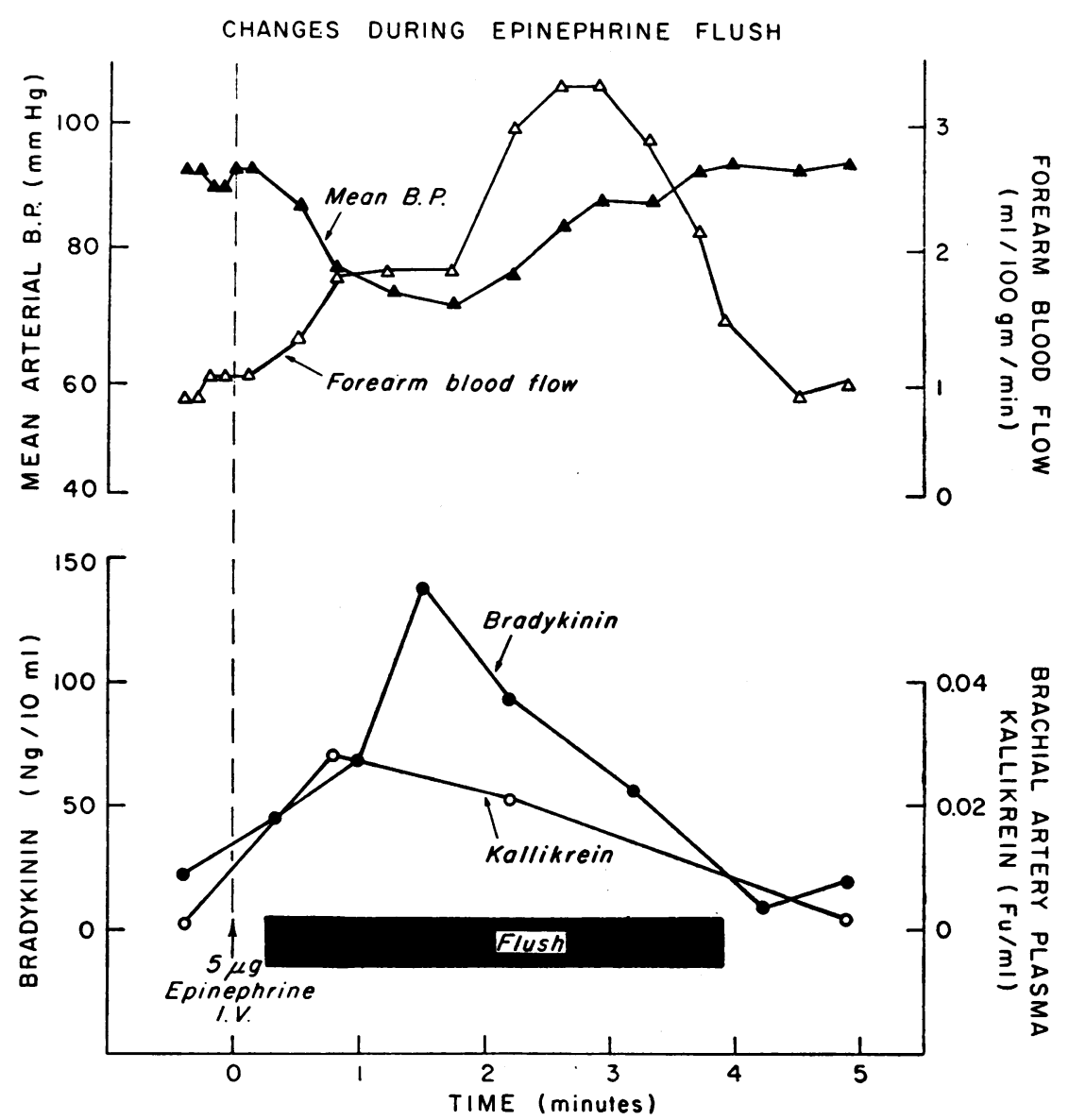

Fig. 4. Serial determinations of mean arterial pressure (BP) (SOlid triANGLES), FOREARM BLOOD FLOW (OPEN TRIANGLES), BRADYKININ (CLOSED CIRCLES), AND RALLIKREIN (OPEN CIRCLES), BEFORE AND AFTER EPINEPHRINE IN CARCINOID PATIENT C.G. The lower than normal control values for forearm blood flow are compatible with the fact that the patient was in congestive heart failure (17).

the values for systemic arterial kallikrein were determined in seven carcinoid patients and are shown in Figure 3. A marked elevation of the enzyme from $1.7 \pm 0.6$ to $12.8 \pm 3.8 \mathrm{FU}$ per $\mathrm{ml}$ $(p<0.05)$ occurred after administration of the drug. In the four patients in whom systemic arterial bradykinin was also measured, this substance rose strikingly from an average of $11.4 \pm$ 3.6 to $77.5 \pm 22.8 \mu \mathrm{g}$ per $10 \mathrm{ml}(\mathrm{p}<0.05)$ after epinephrine (Figures 2 and 4 ). In patient C.G., the hepatic venous bradykinin rose from $15 \mu \mathrm{g}$ per $10 \mathrm{ml}$ to 227 after drug administration. Also in patient C.G., in whom brachial arterial levels of kallikrein and bradykinin were determined serially for 5 minutes after epinephrine, both the enzyme and the kinin were elevated markedly (Figure 4).
In this patient, the vascular and chemical findings were essentially identical after three successive injections of epinephrine.

\section{Cold stimulation: normal subjects}

Hemodynamic findings. The effects of this intervention were studied in nine normal subjects; the results are summarized in Table I and Figure 5. During ice water stimulation, the mean arterial pressure increased, the forearm flow decreased, the forearm resistance was elevated, and the venous tone increased. Cutaneous flushes were not induced by this intervention. The post-Valsalva overshoot of systolic arterial pressure averaged $30.4 \pm 6.2 \mathrm{~mm} \mathrm{Hg}$. 

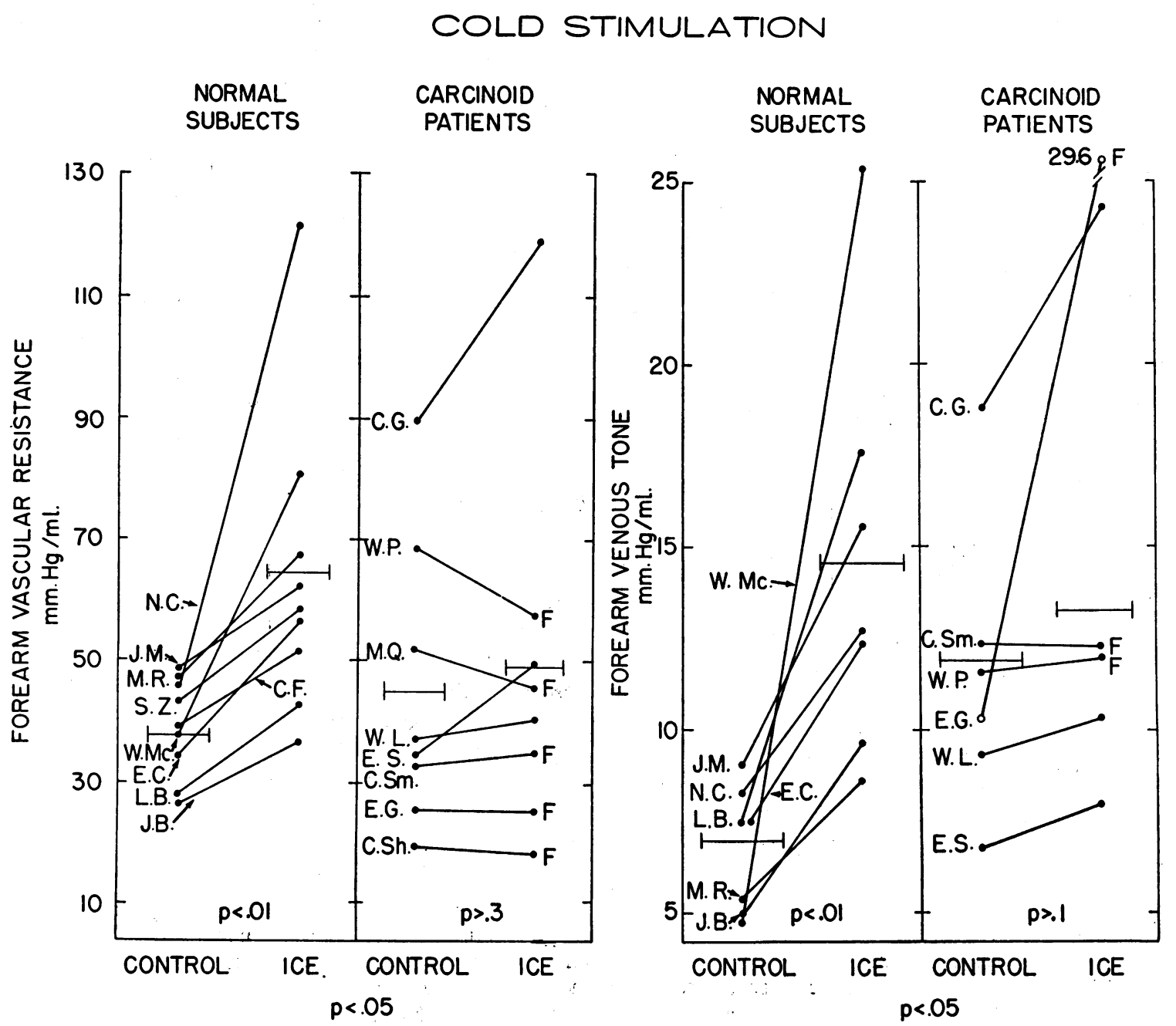

Fig. 5. VAlues FOR FOREARM VASCULAR RESISTANCE AND FOREARM VENOUS TONE DURING THE CONTROL PERIOD AND DURING ICE IMMERSION IN NORMAL SUBJECTS AND CARCINOID PATIENTS. The measurements during cold stimulation illustrate the maximal effects that were observed. In the last panel, the values for venous tone in patient E.G. (open circles) are not included in the calculation of the mean values or probability figures. For further explanation, see legend to Figure 1.

Kallikrein. The effects of cold stimulation on systemic arterial kallikrein were studied quantitatively in nine subjects; the results are given in Figure 6 . No change was observed during the intervention.

\section{Cold stimulation: carcinoid patients}

Hemodynamic findings. The results obtained from eight carcinoid patients are shown in Table I and Figure 5. These results differed strikingly from those observed in the normal subjects. There was no significant alteration of forearm blood flow, forearm resistance, and venous tone $(>0.1)$. Furthermore, the vascular resistance was observed to decrease in three patients and the venous tone to remain essentially unchanged in three. The values for venous tone in patient E.G. are not included in the above analysis. The effects of cold stimulation in the carcinoid patients on vascular resistance and venous tone were significantly different from those recorded in the normal subjects $(p<0.05)$. Again, in contrast to the normal subjects, cutaneous flushes typical of those observed spontaneously in the carcinoid 


\section{COLD STIMULATION \\ NORMAL CARCINOID \\ SUBJECTS PATIENTS}

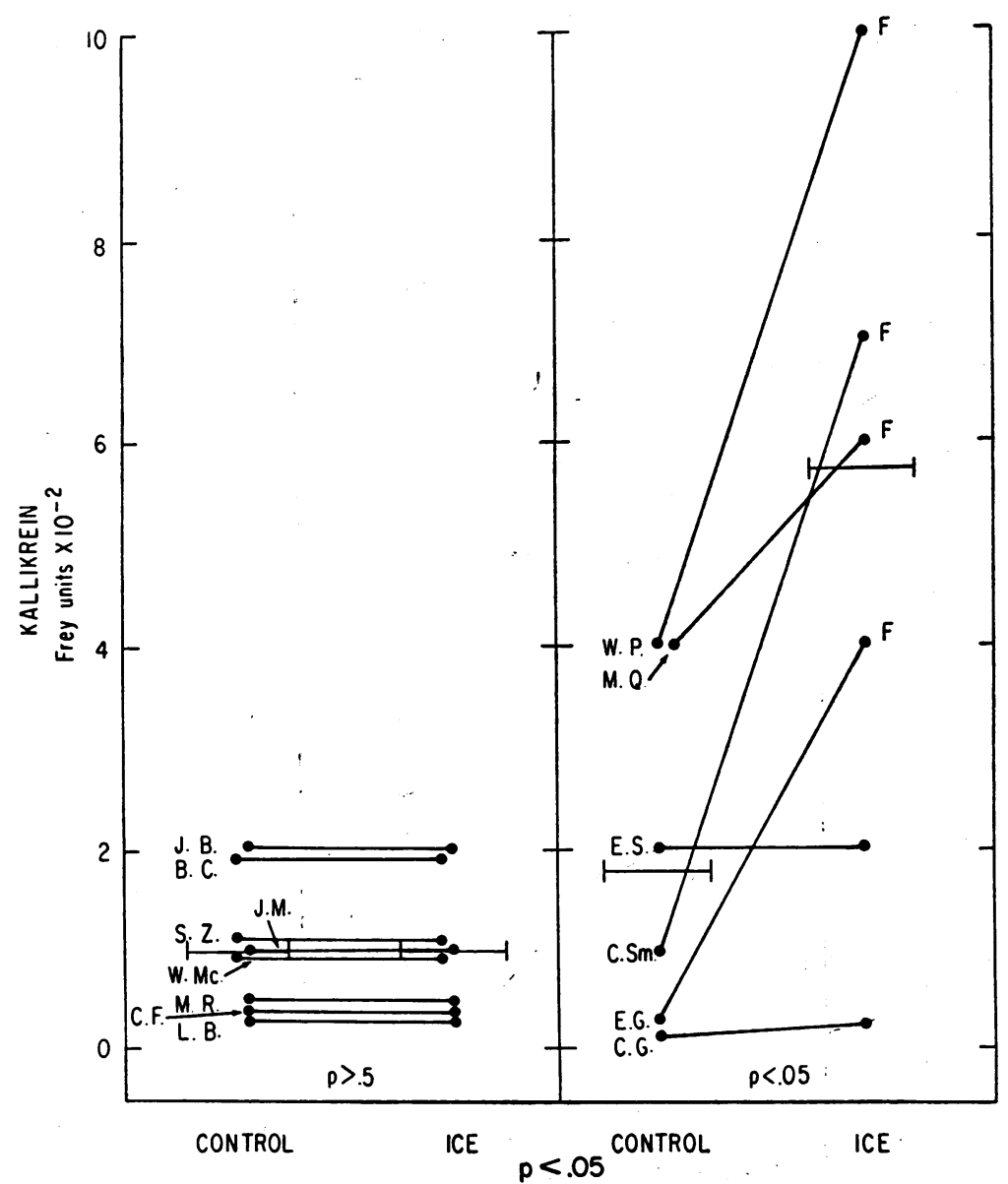

Fig. 6. VALUES FOR ARTERIAL PLASMa KALLIKREIN DURING THE CONTROL PERIOD AND DURING COLD STIMULATION IN THE NORMAL SUBJECTS AND IN CARCINOID PATIENTS. For explanation of comparisons analyzed by probability values, see legend to Figure 1.

syndrome were noted in five of the patients 30 to 60 seconds after cold immersion was begun. Interestingly, in the patients exhibiting flushes, three actually had a decline of vascular resistance, whereas the other two had essentially no change. In contrast, the vascular resistance rose markedly in the three patients who did not flush. In the carcinoid patients, the post-Valsalva overshoot of systolic arterial pressure averaged $21.6 \pm 7.8 \mathrm{~mm}$ $\mathrm{Hg}$ and did not differ significantly $(\mathrm{p}>0.5)$ from that observed in the normal subjects.
Kallikrein. Quantitative measurements of systemic arterial kallikrein were made before and during cold stimulation in six patients; the results are summarized in Figure 6 . In marked contrast to the normal subjects, a striking increase in the enzyme occurred in four patients, each of whom exhibited flushes. The increase in kallikrein from $1.9 \pm 0.8$ to $4.9 \pm 1.4 \mathrm{FU}$ per $\mathrm{ml}$ was statistically significant $(p<0.05)$ for the group as a whole. Furthermore, this response was significantly different from that observed in the normal subjects $(p<0.05)$. 


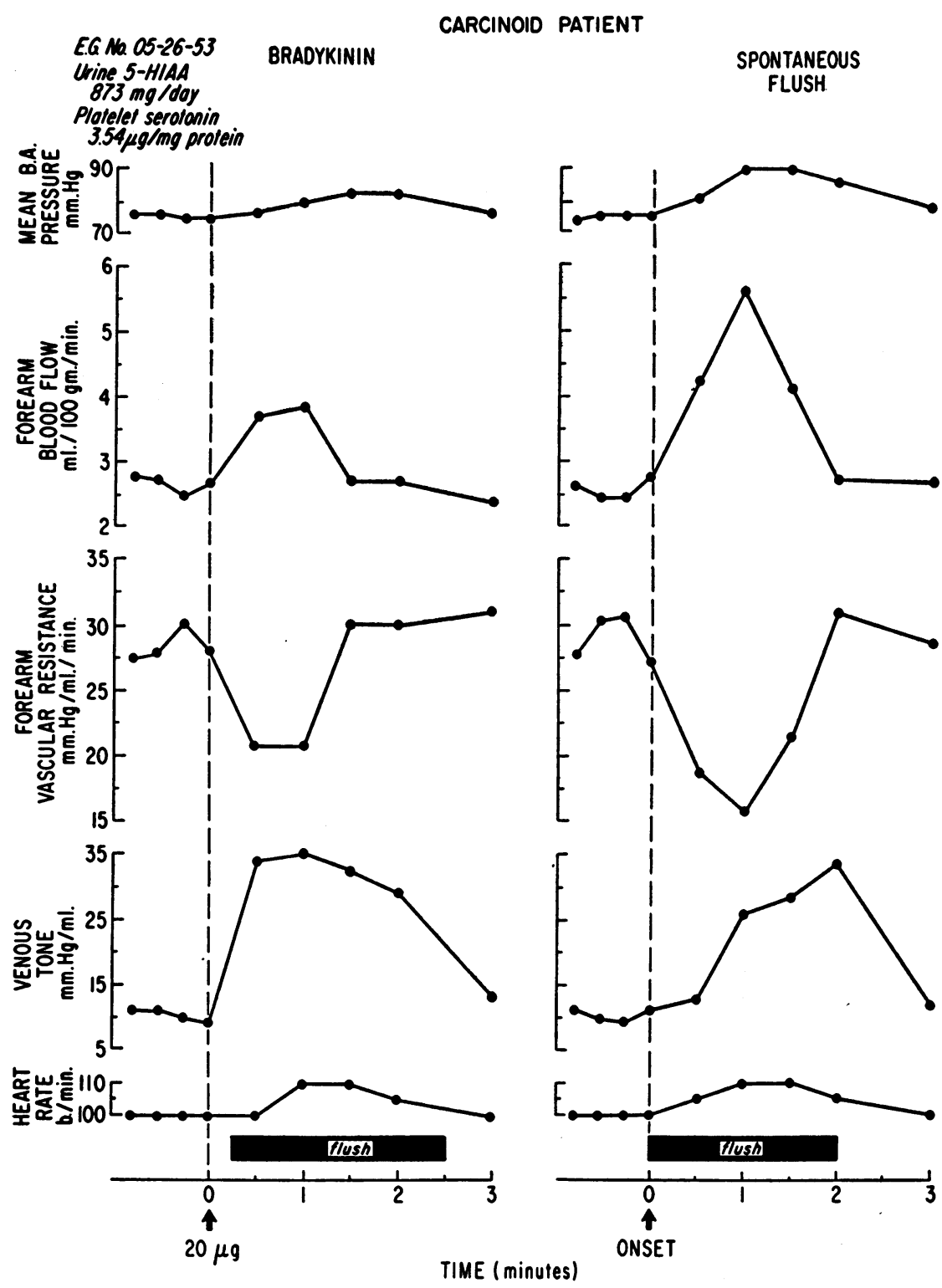

Fig. 7. SERIAL determinations OF HEMOdYNAMic VARIAbles BEFore AND AFTER BRADYKININ AND BEFORE AND DURING A SPONTANEOUS FLUSH IN CARCINOID PATIENT E.G.

Methoxamine: normal subjects, hemodynamic findings

In nine normal subjects, methoxamine elevated the mean arterial pressure, did not change forearm blood flow, but raised vascular resistance; there was no alteration of venous tone. No flush of the skin was observed.
Methoxamine: carcinoid patients, hemodynamic findings

The effects of this agent were studied in four carcinoid patients. The results did not differ significantly $(p>0.5)$ from those elicited in the normal subjects. No cutaneous flush was observed. 


\section{Spontaneous flush: carcinoid patients}

Hemodynamic findings. The effects of a spontaneous flush were observed in three patients. In each of the patients a marked increase in forearm blood flow and a decline in vascular resistance occurred. In addition, the mean arterial pressure fell strikingly in C.Sh. and M.Q. Venous tone was not measured in these two patients. In E.G., an atypical response during several spontaneous flushes was observed (Figure 7). Although the vascular resistance fell as a result of a marked increase in flow, the mean arterial pressure rose. The forearm venous tone increased strikingly during several spontaneous flushes recorded in the laboratory.

Bradykinin. In patient M.Q., bradykinin increased from a control value of $1.2 \mu \mathrm{g}$ per $10 \mathrm{ml}$ to 170.0 during the episode.

\section{Discussion}

Convincing evidence now indicates that serotonin(5-hydroxytryptamine) is not solely responsible for the typical flush in the carcinoid syndrome (3-8). Although this substance is frequently produced in large amounts by carcinoid tumors and is generally recognized as the characteristic chemical abnormality of the syndrome (1-3), its role in the pathogenesis of the syndrome's complex manifestations recently has undergone critical examination (3). Indeed, several investigators have clearly documented the absence of a relationship between the indexes of increased serotonin production and flushing episodes $(6,7,28,29)$. Although carcinoid tumors can produce abnormal quantities of histamine (2), catecholamines (10), and 5-hydroxytryptophan (9), these aberrations are sporadic and cannot account for flushes that are so frequently seen in the syndrome (3). Recently, interest has centered about the role of plasma kinin polypeptides in the flush mechanism. The nonapeptide bradykinin and the decapeptide lysyl-bradykinin are potent endogenous polypeptides formed by the action of proteolytic enzymes (kallikrein) on a relatively specific substrate (kininogen, an $\alpha_{2}$-globulin) formed in the liver and found in abundance in the plasma (30). Anionic kallikreins are found normally in a variety of tissues and, in addition, have been identified in some carcinoid tumors $(4,11)$. Oates and co-work- ers have shown that the epinephrine-provoked flushes in some carcinoid patients were associated with elevation of hepatic venous content of bradykinin (4). Since epinephrine is known to release tissue kallikrein in certain experimental preparations (31), it has been postulated that inactive anionic kallikrein is activated and released from hepatic tumor metastases under a variety of circumstances and in this manner initiates the formation of vasoactive peptides $(4,8,11-13,32,33)$.

One of the major purposes of this study was to characterize the vascular changes of the arteriolar and venous beds in the forearms of carcinoid patients during induced and spontaneous flushes and to compare these findings with those observed in normal subjects who underwent the same interventions. Since a vasoactive substance is thought to be produced in the carcinoid patients but not in the normal subjects, the presence of such an agent might be detected by examination of the vascular dynamics in the forearm. It was observed in the normal subjects that bradykinin reduced systemic arterial pressure and simultaneously increased forearm blood flow. These findings indicate that the drug dilated the resistance vessels of the forearm. In addition, bradykinin resulted in brief venoconstriction during the phase of arterial hypotension, followed by venodilatation. These findings have been documented and discussed in detail (34). In the carcinoid patients, the present investigation has shown that bradykinin results in essentially identical alterations of the arteriolar and venous beds of the forearm (Figure 2). In the two groups of individuals, a cutaneous flush that began over the face and then spread to the neck, trunk, and upper extremities was elicited. These flushes were identical to the flushing episodes witnessed during spontaneous attacks in these and other carcinoid patients. The control values for venous tone in the carcinoid patients were found to be significantly higher than those in the normal subjects. Since three of the patients were in heart failure secondary to carcinoid heart disease (35), this finding is consistent with previous investigations that have shown venoconstriction to attend the heart failure state (17).

The effects of epinephrine in the normal subjects and the carcinoid patients were of particular interest. In the normal subjects the catecholamine resulted in a fall in arterial pressure and a 
rise in forearm flow, thereby producing a decline in forearm vascular resistance (Figures 1 and 2). Venous tone, measured simultaneously, was observed to increase markedly. These findings in normal subjects are consistent with those of previous investigations (36-39). The actions of epinephrine in the carcinoid patients differed strikingly from those in the normal subjects. The carcinoid patients flushed after epinephrine administration. This was associated with a marked decline of forearm resistance that was significantly longer than in the normal subjects (Figure 2), indicating that a substantial portion of the vascular phenomena might be the result of an indirect effect of epinephrine. In addition, the effects of the drug on venous tone contrasted with those in the normal subjects. The carcinoid patients showed no significant alteration of the capacitance vessels in the forearm. In a few, obvious venodilatation occurred, instead of venoconstriction, which was consistently observed in normal subjects (Figure 1). The modification of epinephrine response of the vascular bed in the carcinoid patients may be explained by the formation of a vasodilator substance, such as bradykinin induced by catecholamines. The fact that the onset of the flush induced by epinephrine was significantly more de layed than that noted after bradykinin (Figure 2) is consistent with the postulation that epinephrine resulted in the formation of a vasodilator substance.

The vascular changes observed in the carcinoid patients at the time of activation of the sympathetic nervous system during cold stimulation were clearly in contrast to those found in the normal subjects. In each subject of the latter group, marked arteriolar and venous constriction occurred (Figure 5). The circulatory effects of ice immersion have been reported in detail elsewhere, and the usefulness and reproducibility of this reflex in the study of sympathetic response have been substantiated (18). In the carcinoid patients, it' was observed that no consistent changes in vascular resistance or venous tone were produced (Figure $5)$. In the majority of the patients, a cutaneous flush compatible with a bradykinin-induced reaction was elicited. Interestingly, the most marked discrepancies of the vascular responses between the two groups of individuals were noted in those patients who flushed. The fact that the vascular constrictor responses were markedly attenuated during ice water stimulation is compatible with the formation of a vasodilator in the circulation.

Since it has been shown that catechol sympathomimetic agents in addition to epinephrine (i.e., isoproterenol and norepinephrine) may provoke flushes and paradoxical hypotensive responses in carcinoid patients $(6,7)$, it was of interest to investigate the vascular effects of the noncatechol sympathomimetic pressor agent methoxamine. This alpha-adrenergic stimulating drug, which acts independent of catecholamine release (38), produced similar actions on the forearm vasculature in normal and carcinoid patients (arteriolar constriction, no essential change of venous tone, and no flush).

The other major purpose of this investigation was to correlate changes in arterial blood concentrations of anionic kallikrein and bradykinin with the vascular phenomena during flushing. Since it is postulated that the release of kallikrein from tumor tissue might be the initiating event in the flush reaction, the arterial blood levels of this enzyme were determined before and during induced flushes. Although the control values for kallikrein in the two groups were not statistically different, some of the carcinoid patients had enzyme levels above the highest values noted in the normal subjects. Subjects without carcinoid tumors had very small amounts of the enzyme before and exhibited no change of these values or flushes after administration of epinephrine (Figures 2 and 3 ). In contrast, marked elevations of both arterial blood kallikrein (Figures 2, 3, and 4) and bradykinin (4to 20 -fold increases) and hepatic venous kallikrein were observed in the carcinoid patients during epinephrine-induced flushes. Values of bradykinin did not change significantly in normal subjects. These observations, which indicate that kallikrein is released and bradykinin is formed during flushing, are augmented by the studies of the levels of arterial blood kallikrein during cold stimulation (Figure 6). In each of the carcinoid patients who exhibited flushes during this manuever, there was an elevation of the enzyme after the onset of the cold pressor test. In contrast, kallikrein concentrations remained normal in the carcinoid patients who did not flush and in normal subjects (Figure $6)$.

In each of the carcinoid patients in whom spontaneous flushes were observed, profound reduction 
of forearm arteriolar resistance was demonstrated during flushing (Figure 7 ). The decrease in vascular resistance was similar to that found after the injection of bradykinin. Significantly, in one carcinoid patient the level of arterial bradykinin was found to be elevated during a spontaneous flushing episode.

Although there is usually a marked fall in systemic arterial pressure in carcinoid patients during spontaneous or induced flushes, an elevation of arterial pressure was consistently observed in one patient, E.G., in this series (Figure 7). Since the forearm blood flow increased markedly in this patient during flushing, the calculated forearm vascular resistance actually diminished as it did in the other carcinoid patients. In contrast to the other patients, forearm venous tone increased during spontaneous and bradykinin-, epinephrine-, and ice immersion-induced flushing attacks. This venomotor response provides a physiologic explanation for the elevation of arterial pressure in this patient. It is known that in an occasional patient with carcinoid tumor, serotonin is released during induced flushes $(5,6,40)$, and in these instances it has been postulated that the flush syndrome may result from the combined effects of bradykinin and serotonin. It is known that serotonin can produce venoconstriction (36) as well as arteriolar dilatation $(36,41-46)$, and since patient E.G. had the highest basal levels of platelet serotonin and urinary 5-HIAA of the patients studied, serotonin may have modified the vascular response during flushing attacks (47). Finally, it should be stressed that patient E.G. had a primary bronchial carcinoid tumor with metastasis (5). As we have reported previously, patients with bronchial carcinoid tumors have a distinctive clinical syndrome and exhibit prolonged flushing attacks in which serotonin may be involved (5).

\section{Summary}

The effects of bradykinin, epinephrine, and reflex stimulation of the sympathetic nervous system on the arteries and veins of the forearm were studied and compared in ten normal subjects and eight patients with carcinoid tumors. Forearm blood flow was measured with a strain gauge plethysmograph, forearm vascular resistance was calculated, and venous tone was.assessed by a venous occlusion technique. Bradykinin-induced flushes resulted in dilatation of the arteries and veins in both groups of individuals. Epinephrine produced flushes only in the carcinoid patients and resulted in more profound arteriolar dilatation and less venous constriction than observed in the normal subjects. Cold stimulation produced flushes and an attenuated vascular constrictor response in the majority of carcinoid patients. In addition, arteriolar dilatation was observed during spontaneous flushes in patients with carcinoid tumors. Elevations of peripheral arterial blood concentrations of bradykinin peptide and anionic kallikrein were detected during flushes provoked by these interventions. This investigation provides additional evidence implicating the kallikrein-bradykinin system in the production of the carcinoid flush and in the modification of vascular responses to standard stimuli.

\section{Acknowledgment}

We gratefully acknowledge the determination of the arterial blood bradykinin concentrations by Dr. Marion Webster.

\section{References}

1. Sjoerdsma, A., H. Weissbach, L. L. Terry, and S. Udenfriend. Further observations on patients with malignant carcinoid. Amer. J. Med. 1957, 23, 5.

2. Pernow, B., and J. Waldenström. Determination of 5-hydroxytryptamine, 5-hydroxyindole acetic acid and histamine in thirty-three cases of carcinoid tumor (argentaffinoma). Amer. J. Med. 1957, 23, 16.

3. Sjoerdsma, A., and K. L. Melmon. The carcinoid spectrum. Gastroenterology 1964, 47, 104.

4. Oates, J. A., K. Melmon, A. Sjoerdsma, L. Gillespie, and D. T. Mason. Release of a kinin peptide in the carcinoid syndrome. Lancet 1964, 1, 514.

5. Melmon, K. L., A. Sjoerdsma, and D. T. Mason. Distinctive clinical and therapeutic aspects of the syndrome associated with bronchial carcinoid tumors. Amer. J. Med. 1965, 39, 568.

6. Robertson, J. I. S., W. S. Peart, and T. M. Andrews. The mechanism of facial flushes in the carcinoid syndrome. Quart. J. Med. 1962, 31, 103.

7. Levine, R. J., and A. Sjoerdsma. Pressor amines and the carcinoid flush. Ann. intern. Med. 1963, 58, 818.

8. Fox, T. New light on carcinoid flush (editorial). Lancet 1964, 1, 539.

9. Oates, J. A., and A. Sjoerdsma. A unique syndrome associated with secretion of 5-hydroxytryp- 
tophan by metastatic gastric carcinoids. Amer. J. Med. 1962, 32, 333.

10. Von Studnitz, W. On the excretion of 3-methoxy-4hydroxymandelic acid in patients with serotonin producing tumours. Scand. J. clin. Lab. Invest. 1959, 11, 309.

11. Melmon, K. L., W. Lovenberg, and A. Sjoerdsma. Characteristics of carcinoid tumor kallikrein: identification of lysyl-bradykinin as a peptide it produces in vitro. Clin. chim. Acta 1965, 12, 292.

12. Melmon, K., W. Lovenberg, J. A. Oates, L. Gillespie, Jr., and A. Sjoerdsma. Implication of the kallikrein system in production of the carcinoid flush (abstract). J. clin. Invest. 1964, 43, 1308.

13. Oates, J. A., W. A. Pettinger, and R. B. Doctor. Evidence for the release of bradykinin in carcinoid syndrome. J. clin. Invest. 1966, 45, 173.

14. Udenfriend, S., H. Weissbach, and B. B. Brodie. Assay of serotonin and related metabolites, enzymes and drugs. Meth. biochem. Anal. 1958, 6, 95.

15. Weissbach, H., and B. G. Redfield. Factors affecting the uptake of 5-hydroxytryptamine by human platelets in an inorganic medium. J. biol. Chem. 1960, 235, 3287.

16. Jepson, J. B. Paper chromatography of urinary indoles. Lancet 1955, 2, 1009.

17. Mason, D. T., and E. Braunwald. Studies on digitalis. $X$. Effects of ouabain on forearm vascular resistance and venous tone in normal subjects and in patients in heart failure. J. clin. Invest. 1964, 43, 532.

18. Mason, D. T., and E. Braunwald. Effects of guanethidine, reserpine, and methyldopa on reflex venous and arterial constriction in man. J. clin. Invest. $1964,43,1449$.

19. Whitney, R. J. The measurement of volume changes in human limbs. J. Physiol. (Lond.) 1953, 121, 1.

20. Ryder, H. W., W. E. Molle, and E. B. Ferris, Jr. The influence of the collapsibility of veins on venous pressure, including a new procedure for measuring tissue pressure. J. clin. Invest. 1944, 23, 333.

21. Holling, H. E., H. C. Boland, and E. Russ. Investigation of arterial obstruction using a mercury-in-rubber strain gauge. Amer. Heart J. 1961, 62, 194.

22. Mason, D. T., and E. Braunwald. A simplified plethysmographic system for the measurement of systemic arterial pressure and peripheral blood flow. Amer. Heart J. 1962, 64, 796.

23. Bevegård, B. S., and J. T. Shepherd. Effect of local exercise of forearm muscles on forearm capacitance vessels. J. appl. Physiol. 1965, 20, 968.

24. Brown, E., A. D. M. Greenfield, J. S. Goei, and G. Plassaras. Filling and emptying of the lowpressure blood vessels of the human forearm. $\mathrm{J}$. appl. Physiol. 1966, 21, 573.
25. Elliott, D. F., G. P. Lewis, and E. W. Horton. The structure of bradykinin: a plasma kinin from ox blood. Biochem. biophys. Res. Commun. 1960, 3, 87.

26. Webster, M. E., and J. V. Pierce. The nature of the kallidins released from human plasma by kallikreins and other enzymes. Ann. N. Y. Acad. Sci. 1963, 104, 91.

27. Webster, M. E., and J. P. Gilmore. The estimation of the kallidins in blood and urine. Biochem. Pharmacol. 1965, 14, 1161.

28. Dubach, U. C., and O. R. Gsell. Carcinoid syndrome. Effective symptomatic treatment. Amer. Heart J. 1963, 65, 425.

29. Davis, R. B., and J. C. Rosenberg. Carcinoid syndrome associated with hyperserotoninemia and normal 5-hydroxyindoleacetic acid excretion. Amer. J. Med. 1961, 30, 167.

30. Douglas, W. W. 5-Hydroxytryptamine and antagonists; polypeptides-angiotensin and kinins in The Pharmacological Basis of Therapeutics, 3rd ed., L. S. Goodman and A. Gilman, Eds. New York, Macmillan, 1965 , p. 644.

31. Hilton, S. M., and G. P. Lewis. The relationship between glandular activity, bradykinin formation and functional vasodilatation in the submandibular salivary gland. J. Physiol. (Lond.) 1956, 134, 471.

32. Erdös, E. G., A. G. Renfrew, E. M. Sloan, and J. R. Wohler. Enzymatic studies on bradykinin and similar peptides. Ann. N. Y. Acad. Sci. 1963, 104, 222.

33. Von Euler, U. S., and J. H. Gaddum. An unidentified depressor substance in certain tissue extracts. J. Physiol. (Lond.) 1931, 72, 74.

34. Mason, D. T., and K. L. Melmon. Effects of bradykinin on forearm venous tone and vascular resistance in man. Circulat. Res. 1965, 17, 106.

35. Roberts, W. C., and A. Sjoerdsma. The cardiac disease associated with the carcinoid syndrome (carcinoid heart disease). Amer. J. Med. 1964, 36, 5.

36. Sharpey-Schafer, E. P., and J. Ginsburg. Humoral agents and venous tone. Effects of catecholamines, 5-hydroxytryptamine, histamine, and nitrites. Lancet 1962, 2, 1337.

37. Whelan, R. F., and I. S. de la Lande. Action of adrenaline on limb blood vessels. Brit. med. Bull. 1963, 19, 125.

38. Innes, I. R., and M. Nickerson. Drugs acting on postganglionic adrenergic nerve endings and structures innervated by them (sympathomimetic drugs) in The Pharmacological Basis of Therapeutics, 3rd ed., L. S. Goodman and A. Gilman, Eds. New York, Macmillan, 1965, p. 477.

39. Ahlquist, R. P. A study of the adrenotropic receptors. Amer. J. Physiol. 1948, 153, 586.

40. Peart, W. S., T. M. Andrews, and J. I. S. Robertson. Carcinoid syndrome. Serotonin release induced with intravenous adrenaline or noradrenaline. Lancet $1961,1,577$. 
41. Roddie, I. C., J. T. Shepherd, and R. F. Whelan. The action of 5-hydroxytryptamine on the blood vessels of the human hand and forearm. Brit. J. Pharmacol. 1955, 10, 445.

42. Sjoerdsma, A., H. Weissbach, and S. Udenfriend. A clinical, physiologic and biochemical study of patients with malignant carcinoid (argentaffinoma). Amer. J. Med. 1956, 20, 520.

43. Schwaber, J. R., and D. S. Lukas. Hyperkinemia and cardiac failure in the carcinoid syndrome. Amer. J. Med. 1962, 32, 846.

44. McCubbin, J. W., Y. Kaneko, and I. H. Page. Inhibition of neurogenic vasoconstriction by sero- tonin. Vasodilator action of serotonin. Circulat. Res. 1962, 11, 74.

45. Page, I. H., and J. W. McCubbin. The variable arterial pressure response to serotonin in laboratory animals and man. Circulat. Res. 1953, 1, 354.

46. Haddy, F. J., P. Gordon, and D. A. Emanuel. The influence of tone upon responses of small and large vessels to serotonin. Circulat. Res. 1959, 7, 123.

47. Vane, J. R. The actions of sympathomimetic amines on tryptamine receptors in Adrenergic Mechanisms, J. R. Vane, Ed. Boston, Little, Brown, 1961, p. 356. 